\title{
LIII. On conditions controlling the drop of potential at the electrodes in vacuum-tube discharge.-(Second paper)
}

\section{Clarence A. Skinner}

To cite this article: Clarence A. Skinner (1902) LIII. On conditions controlling the drop of potential at the electrodes in vacuum-tube discharge.-(Second paper), Philosophical Magazine Series 6, 4:22, 490-504, DOI: 10.1080/14786440209462869

To link to this article: http://dx.doi.org/10.1080/14786440209462869

曲 Published online: 15 Apr 2009.

Submit your article to this journal $[\pi$

Џll Article views: 2

Q View related articles $\longleftarrow$

Citing articles: 1 View citing articles 5 


\section{$[490]$}

LIII. On Conditions controlling the Drop of Potential at the Electrodes in Vacuum-tube Discharge.-(Second Paper*). By Clanence A. Skinner, Adjunct Professor of Physics, University of Nebraskat.

7 HE results of experiments described in a former communication seem to indicate that the drop of potential at the electrodes in vacuum-tube discharge is caused by a resistance to discharge of the gas ion to the metal electrode, this resistance increasing with the velocity with which the ion impinges on the electrode. To explain this it is conceived that the discharging ion must give up its kinetic energy with-or before it can give up-its charge. Different physicists have suggested that at least a momentary chemical combination takes place between the carrier and the electrode. It is very plausible then that the elastic reaction of the ion impinging on the electrode introduces a force resisting discharge, the resistance increasing with the velocity of impact. This being true, the ions approaching the electrode will accumulate at its surface until the thereby increased electric intensity becomes sufficient to cause as many to discharge in a given interval as arrive at the electrode during the same interval. From this standpoint the drop of potential. will depend on the time required for the discharging ions, arriving with a definite velocity, to come to rest at the electrode-their kinetic energy being first given up by collision with both the neighbouring gas molecules and the electrode.

This being a mechanical explanation of the phenomena the laws of mechanics should be applicable in deducing and in predicting experimental results. The complicated nature of the problem, however, presents at present a discouraging barrier to any rigid mathematical discussion, but a simplified case may be considered in order to test the applicability of the view.

Suppose perpendicular to the plane of the figure (fig. 1) a plane electrode OA. Moving freely in the direction $a \mathrm{O}$ perpendicular to the electrode is a particle of mass $m$ carrying a positive charge $e$. This particle is supposed to be driven towards the electrode by a uniform field equal to

$$
\frac{\mathrm{V}_{a}-\mathrm{V}_{0}}{a \mathrm{O}} \frac{\mathrm{V}}{s^{2}}
$$

* The first paper under this title was published in the Phil. Mag. of Dec. 1901.

† Communicated by the Author, having been read before the American Association for the Advancement of Science, June 1902. 
where $V$ is the fall of potential from $a$ to $O$, and $s$ the distance. The force accelerating the particle is

$$
\frac{\mathrm{V}}{\mathrm{s}} e \text {, }
$$

and the acceleration produced

$$
\frac{\mathrm{Ve}}{\mathrm{sin}} \text {. }
$$

Fig. 1.

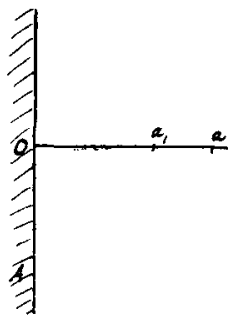

The kinetic energy of the mass when it reaches $\mathrm{O}$ is given by the expression

$$
\left(\frac{1}{2} m u^{2}+\mathrm{V} e\right)
$$

where $u$ is the velocity of the particle at $a$, and Ve the work done by the field on the charge $e$ in moving from $a$ to $O$.

The energy with which the particle rebounds is

$$
\left(\frac{1}{2} m u^{2}+\mathrm{V} e\right) k^{2} \text {, }
$$

where $k$ is the coefficient of restitution $* 0<k<1$. Under the energy of rebound it moves against the field with a decreasing velocity, coming to rest say at $a_{1}$ from which position it is again driven by the field to the electrode, reaching it with the same energy with which it left it. The energy with which it rebounds in the second case must be

likewise for the third

$$
\left(\frac{1}{2} m u^{2}+\mathrm{V} e\right) k^{4}
$$

and so on.

$$
\left(\frac{1}{2} m u^{2}+\mathrm{V} e\right) k^{6}
$$

We wish to find the time required for the particle to come to rest at the electrode-it being conceived as the time of discharge. This may be obtained by summing the intervals between successive impacts, considering the time of impact as relatively negligible.

* See Tait and Steele, 'Dynamics of a Particle,' p. 345. 
492 Prof. Skinner on Conditions controlling the Drop of

The time $t_{1}$ elapsing between the first and second impacts may be readily obtained by combining the equation of uniformly accelerated motion

$$
s_{1}=\frac{1}{2} \operatorname{se} e\left(\frac{t_{1}}{2}\right)
$$

(where $s_{1}=\mathrm{O} a_{1}$, and $t_{1} / 2$ the time required to pass over that space) with that of energy,

which gives

$$
\frac{\mathrm{V} e}{s} \cdot s_{1}=\left(\frac{1}{2} m \iota^{2}+\mathrm{V} e\right) k^{2},
$$

$$
t_{1}=2 s\left[\left(\frac{m}{e}\right)^{2} \frac{u^{2}}{\mathrm{~V}^{2}}+\frac{m}{e}{ }^{2}\right]^{\frac{1}{2}} \dot{k} .
$$

Likewise we obtain the interval $t_{2}$ between the second and third impacts,

$$
t_{2}=2 s\left[\left(\frac{m}{e}\right)^{2} \frac{u^{2}}{\overline{\mathrm{V}}^{2}}+\frac{m 2}{e} \overline{\mathrm{V}}\right]^{\frac{1}{2}} k^{2} ;
$$

between the third and fourth,

and so forth.

$$
t_{3}=2 s\left[\left(\frac{m}{e}\right)^{2} \frac{u^{2}}{\mathrm{~V}^{2}}+\frac{m 2}{\epsilon \mathrm{V}}\right]^{\frac{1}{2}} k^{3},
$$

The time $\mathrm{T}$ required for the particle to come to rest at the electrode is given by the infinite series

$$
\begin{aligned}
\mathrm{T} & =t_{1}+t_{2}+t_{3}+\ldots \\
& =2 s\left[\left(\frac{m}{e}\right)^{2} \frac{u^{2}}{\overline{\mathrm{V}}^{\varepsilon}}+\frac{m}{e} \overline{\mathrm{V}}\right]^{\frac{1}{2}}\left\{k+k^{2}+k^{3}+\ldots\right\},
\end{aligned}
$$

which, the series for $0<k<1$ being convergent and equal to $\frac{k}{1-k}$, gives

$$
\mathrm{T}=\frac{2 s k}{1-k}\left[\left(\frac{m}{e}\right)^{2} \frac{u^{2}}{\mathrm{~V}^{2}}+\frac{m 2}{e \overline{\mathrm{V}}}\right]^{\frac{1}{2}} .
$$

Since $\mathrm{T}$ must be positive, $0<k<1$, and the other quantities chosen positive, the quantity in brackets []$^{\frac{1}{2}}$ must be positive. Assuming this latter has a finite value we have

$$
\begin{array}{cl}
\text { for } & k=0, \quad \mathrm{~T}=0, \\
\text { and for } & k=1, \quad \mathrm{~T}=\infty,
\end{array}
$$

as we should expect-there being no elastic reaction, the particle by first impact sticks to the electrode, while, on the 
Potential at the Electrodes in Vacumm-tube Discharge. 493

other hand, if there be no loss of energy by impact it will not come to rest at all.

Considering now $\nabla$ as the drop of potential at the electrode, and $u$ the velocity with which the ion enters the space orer which this drop takes place, it is evident that

(a) for $u=$ const., $\mathrm{T}$ decreases with increasing values of $\mathrm{V}$ -that is, by increasing the drop at the electrode the discharge of the ion is accelerated ;

(b) for $\mathrm{T}=$ const., $\mathrm{V}$ increases with $u$, which means that to maintain the time of discharge the same the drop at the electrode must increase with the velocity with which the ions move into its field;

(c) for $\mathbf{T}=$ const. and $u=$ const., $\mathrm{V}$ must increase with $(\mathrm{m} / \mathrm{e})$ - that is, other conditions being the same, the greater the ratio of the mass of the ion to its charge the greater must be the electrode drop.

Referring to (a) we explain the existence of a drop of potential wherever the ions move up to and discharge to a conductor. It also explains the fact that a conductor assumes the potential of the condncting gas, in that for $u=0, \mathrm{~T}$ only approaches infinity as $\mathrm{V}$ approaches a zero value. (b) explains the simultaneous increase in drop at the two electrodes, in vacuum-tubes, if with the anode in the cathode dark space they are made to approach each other. For, in this case, the ions reaching one electrode are supposed to have emerged from the space covered by the drop at the other, hence a greater drop at the first producing a greater velocity $u$ at the second necessitates thereby a greater drop at the second. The second acts in the same way on the first, so that there is a mutual increase in the drop at the two electrodes. By $(c)$ the great difference in anode and cathode drops in vacuumtubes may be explained under the view that the ratio $(\mathrm{m} / \mathrm{e})$ for the positive ions is much larger than for the negative, and hence the cathode drop (for the same velocity of approach $u$ at the two electrodes) necessarily much larger at the cathode than at the anode. It is very likely that the difference would be much greater if the gradient (in the negative glow) driving the positive ions into the cathods field were not much smaller than that (in the positive column) driving the negative ions into the anode field.

We find in these examples that the above equation for $\mathrm{T}$, though deduced from an ideal case, furnishes an explanation for many of the phenomena, and we may therefore conclude that it contains the controlling factors, those ignored entering as correcting factors. It is very likely that the electric intensity is not constant within the space covered by the 


\section{Prof. Skinner on Conditions controlling the Drop of}

drop at the electrodes, but in using the total drop we assume a mean value for this intensity which should not make a vital difference in the results. The presence of the netral gas molecules by impeding the motion of the ions should be marked, especially at the higher gas pressures. On the one hand it should aid in destroying the kinetic energy of the ion, on the other it should increase the time between impacts on the electrode; the former would accelerate the discharge, the latter tend to impede it. There is another important factor which is not introduced in the equation, namely, the attraction of the metal used as electrode for the charge on the ion. As pointed out in the first paper, the discharge is facilitated by this attraction, in that on comparing different metals under the same conditions it is found that the drop decreases as the attraction of the metal for the charge carried by the ion increases.

To further test the above view of the cause of the electrode drop the following experiments were performed. The details. of the apparatus are given in the first paper.

\section{Drop at Anode with Potential Gradient in Neighlouring Gias.}

The writer has already called attention $(l . c$.) to the fact that the increase in anode drop with gas pressure may be simply dne to the simultaneous increase in the potential gradient in the positive column-in that with increased gradient the ions must be driven into the anode field with a greater velocity.

By using discharge-tubes of different diameters, in which the potential gradient in the positive column increases as the diameter decreases*, the variation of the anode drop with the potential gradient alone may be obtained.

Three tubes of form shown in fig. 2, having diameters of"

Fig. 2.

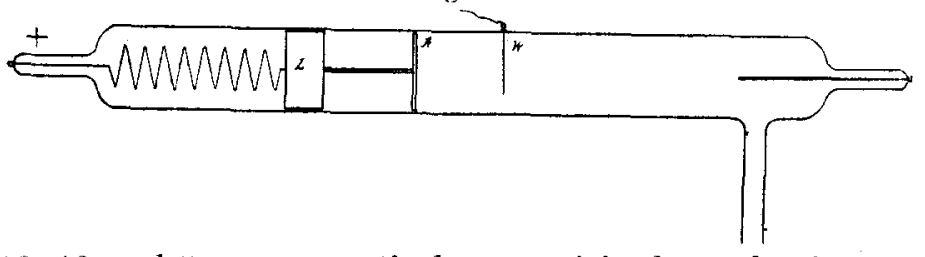

18,12 , and $\measuredangle \mathrm{mm}$. respectively, were joined together in open connexion, very carefully prepared by repeated evacuations and drying, then filled to the desired pressure with atmospheric nitrogen obtained and purified in the usual manner.

* A. Herz, Wied. Ann. liv. p. 244 (1895). 
Potential at the Electrodes in Vacunm-tube Discharge. 495

The disk anode A of polished aluminium (diameter to fit the tube) could be moved to any desired position by the action of a magnet on the iron lug $\mathrm{L}$. By measuring the difference of potential between the inserted wire $W$ and the anode at definite distances, the anode drop and potential gradient in the gas could both be obtained. In seeking the variation of the drop with the force driving the ion into the electrode field, it is obviously necessary that the conditions be so chosen that the potential gradient in the gas possess if possible a constant value up to the boundary of the electrode field. It has been found * that this is not the case at low gas pressures, even though the positive column be unstriated, but that to a certain short distance from the anode the gradient may be very small. This condition is, however, approached as the gas pressure increases, so that at the pressure chosen, $2 \mathrm{~mm}$., the gradient rises to a constant value within a very short distance from the anode. The results obtained, given in Table I. and plotted in fig. 3 (p. 496), show, as expected, a marked increase in the anode drop with the potential gradient.

TABLE I.-Variation of Anode Drop with Potential Gradient in Positive Column.

Gas Pressure constant, $2 \mathrm{~mm}$.

\begin{tabular}{|c|c|c|c|c|}
\hline & $\begin{array}{l}\text { Distance from } \\
\text { anode to ex- } \\
\text { ploring wire } \\
\text { (mit.). }\end{array}$ & $\begin{array}{c}\text { Corre- } \\
\text { sponding } \\
\text { P.D. (rolts). }\end{array}$ & $\begin{array}{l}\text { Drop at } \\
\text { Anode. }\end{array}$ & $\begin{array}{c}\text { Pot. Grad. } \\
\text { in Gas } \\
\text { (volts/em.). }\end{array}$ \\
\hline $\begin{array}{l}\text { Ist Tube (diam. } 18 \mathrm{~mm} \text {.)... } \\
\text { 2nd Tube (diam. } 12 \mathrm{~mm} . \text { ). } \\
\text { 3rd Tube (diam. } 8 \mathrm{~mm} \text {.)... }\end{array}$ & $\begin{array}{r}0 \\
10 \\
20 \\
0 \\
20 \\
0 \\
10 \\
20\end{array}$ & $\begin{array}{r}28.4 \\
95.3 \\
1607 \\
29.9 \\
168.2 \\
335 \\
1089 \\
182.7\end{array}$ & $\begin{array}{c}28 \cdot 4 \\
\ldots \\
29.9 \\
\ldots \\
\ldots \\
\ldots\end{array}$ & $\begin{array}{l}66 \cdot 4 \\
65 \cdot 4 \\
69 \cdot 2 \\
75 \cdot 4 \\
73 \cdot 8\end{array}$ \\
\hline
\end{tabular}

Anti-cathode Effects.

The phenomena attendant upon the crowding of the negative glow by the walls of the discharge-tube, or other obstruction, are on the whole complicated. Hittorf $\dagger$ found that when the negative glow is restricted in its natural expansion it is accompanied by an increased resistance to the passage of a current through the tube. The idea suggesterl itself to the writer that this increased resistance is caused by

* C. A. Skinner, Wied. Amn. lxviii. p. 752 (1899).

$\uparrow$ See J. J. Thomson, Rec. Res. in Elect. and Mag. p. 162. 
496 Prof. Skinner on Conditions controlling the Drop of reduced ionization in the negative glow, which in turn necessitates (for the same current passing) an increased

Fig. 3.

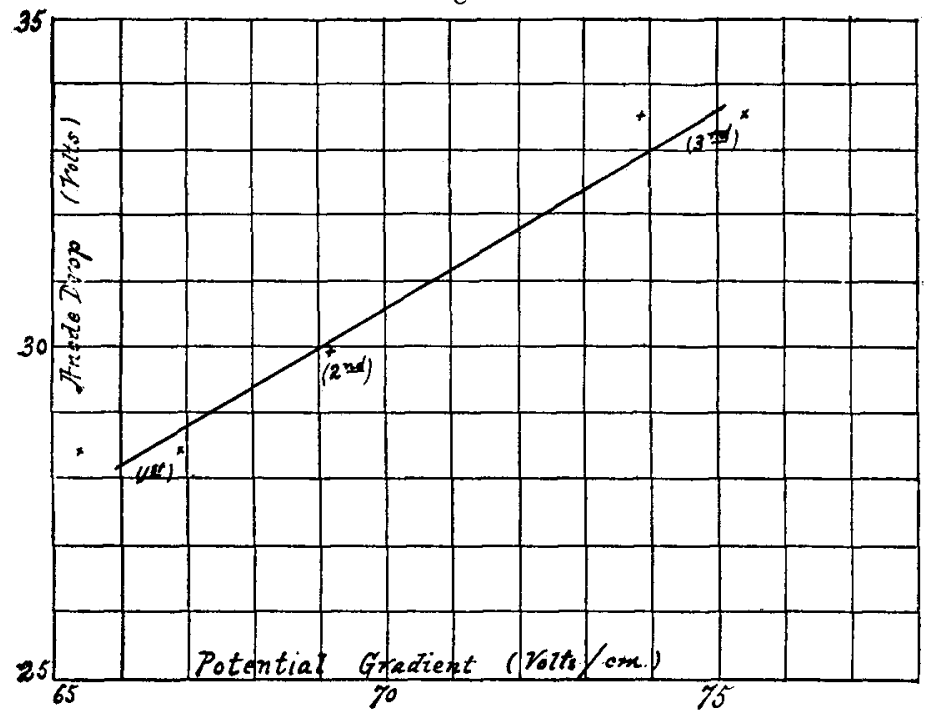

velocity of the ions moving up to the cathode, and hence an increased cathode drop.

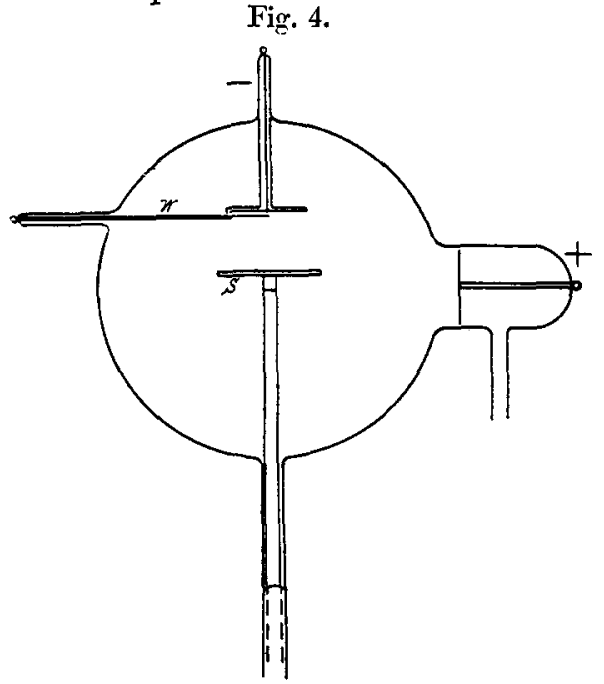

To study this a tube of form shown in fig. 4 was first tried. The cathode was inlaid in guttapercha, its stem 
Potential at the Electrodes in Vacuum-tube Discharge. 497

sheathed in glass tubing. An inserted wire $\mathrm{W}$ was used to obtain the cathode drop. A guttapercha screen $\mathrm{S}$ parallel to and slightly larger than the cathode was mounted on a glass tube entering through a barometer column. 'This screen could be shifted to any desired distance from the cathode and its effect on the drop noted. It was found in this cose, however, that the negative glow was simply reflected by the screen without any change in the cathode drop. Had the screen been replaced by an anode of the same form the drop' would have increased greatly, as previously shown. Though this form of tube was evidently useless for making the lesired study, the above experiment is important in that it shows that the increased drop at the cathode when the anode is brought near* is not, as might be supposed, due to an obstruction.

'Tubes as shown in fig. 5 were then tried. To vary the

Fig. 5.

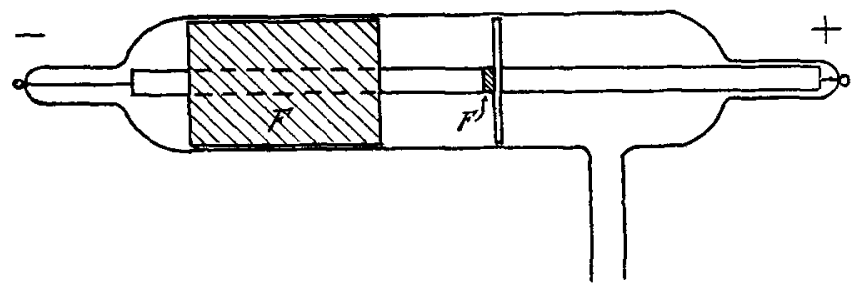

conditions three of different diameters $(11,7$, and $5.5 \mathrm{~mm}$. resp.) were used. In each a steel cathode (diam. 2 mm., exposed length $6 \mathrm{~mm}$.) passed through a guttapercha cylinder, and was capped by a piece of the same material $F$. The anode was a steel disk (fitting tiso tube) placed practically in the negative glow, where its drop is a vanishing quantity. The difference of potential between the terminals of the tube gave, therefore, the cathode drop. The results obtnined were puzzling, and it was thought that the three tubes were not operating under similar conditions. They were taken apart, cleaned, and reconstructed with some slight modification in design, and were tried again with similar results, which are given in Table II. and plotted in fig. 6 (p.499). The curves show at various gas pressures the variation of cathode drop with current.

At a pressure $3.6 \mathrm{~mm}$. the drop in the two larger tubes was practically the same, while the smaller gave a higher value. This was to be expected, for the walls of the smaller tube were already confining the negative glow. At $1 \cdot 2 \mathrm{~mm}$.

* See first paper. 
498 Prof. Skinner on Conditions controlling the Drop of

Tabie II.-Effect of Diameter of Discharge Tube on the Drop at a Co-axial Cylinder Cathode.

Drop at Cathode in Volts.

Diameters :-1st Tube $11 \cdot 0$, 2nd 7,3 rd $5.5 \mathrm{~mm}$.

\begin{tabular}{|c|c|c|c|c|c|c|c|c|c|c|c|}
\hline $\begin{array}{c}\text { Gas } \\
\text { Pressure }\end{array}$ & & 86 & & & $1 \cdot 2$ & & & 0.5 & & & 2. \\
\hline Current. & $\begin{array}{c}\text { 1st } \\
\text { Tube. }\end{array}$ & $\begin{array}{l}\text { Ond } \\
\text { Tube. }\end{array}$ & $\begin{array}{c}\text { 3rd } \\
\text { Tube. }\end{array}$ & $\begin{array}{c}\text { 1st } \\
\text { 'lube. }\end{array}$ & $\begin{array}{l}\text { 2nd } \\
\text { Tube. }\end{array}$ & $\begin{array}{c}\text { 3rd } \\
\text { Tube. }\end{array}$ & $\begin{array}{c}1 \text { st } \\
\text { Tube. }\end{array}$ & $\begin{array}{l}\text { 2nd } \\
\text { Tube. }\end{array}$ & $\begin{array}{c}\text { 3rd } \\
\text { Tube. }\end{array}$ & $\begin{array}{c}\text { 1st } \\
\text { T'ube. }\end{array}$ & $\begin{array}{l}2 \text { ndd } \\
\text { Tube. }\end{array}$ \\
\hline $\begin{array}{l}0.50 \\
0.60 \\
0.70 \\
0.80 \\
0.82 \\
0.90 \\
1.00 \\
1.20 \\
1.50\end{array}$ & $\begin{array}{c}311 ; \\
\ldots \\
\ldots \\
311 ; \\
\ldots \\
3 \ddot{2} 4 \\
: 345\end{array}$ & $\begin{array}{c}\ldots \\
\ldots 17 \\
317 \\
\ldots \\
\ldots 16 \\
: ; 116 \\
: 318\end{array}$ & $\begin{array}{c}\ldots \\
\ldots \\
344 \\
345 \\
\ldots 3 \\
348 \\
350 \\
355\end{array}$ & $\begin{array}{c}367 \\
\ldots \\
\ldots \\
\ldots \\
\ldots \\
\ldots \\
400\end{array}$ & $\begin{array}{c}408 \\
\ldots \\
\ldots \\
\ldots \\
\ldots \\
\ldots \ddot{85}\end{array}$ & $\begin{array}{c}445 \\
\ldots \\
\ldots \\
\ldots \\
\ldots \\
\ldots \\
502\end{array}$ & $\begin{array}{c}605 \\
650 \\
672 \\
695 \\
\dddot{755} \\
820 \\
860\end{array}$ & $\begin{array}{c}573 \\
582 \\
600 \\
630 \\
\ldots \\
\ldots \\
675\end{array}$ & $\begin{array}{c}645 \\
685 \\
723 \\
732 \\
\dddot{755} \\
795\end{array}$ & $\begin{array}{l}776 \\
950\end{array}$ & 980 \\
\hline
\end{tabular}

the negative glow in the two smaller tubes, expanding with decreased pressure, touched the walls, while that in the largest remained still unconfined. At $0.5 \mathrm{~mm}$. the curves are all irregular, but interest centres on the fact that the drop for the largest tube is for all currents above that for the one of intermediate size, while at the higher currents it rises above that for both. Now at this pressure $(0.5 \mathrm{~mm}$.) the negative glow in the largest tube just begins to touch the walls, and to the expansion of the glow with increasing current the form of the curves is probably to be attributed. At lower gas-pressures the battery could not maintain a current sufficient for making a complete set of observations, but it was found on decreasing the pressure that at a certain point the cathode drop for the different tubes gave again normal sequence, the smaller tube in each case possessing the greater drop, as shown by the observations taken at $0.2 \mathrm{~mm}$.

These results are explicable when we consider as the ionizing agent the negative ion shot forth with a high velocity from the immediate vicinity of the cathode. The ionization from which the cathode draws its current is largely produced in the negative glow. Beyond the negative glow the ion does not posess sufficient velocity to further ionize the gas. If now in its course the ionizing particle impinges on the wall of the tube it must rebound with a loss of energy. With an incident velocity sufficiently large it should, after impact on the wall, possess a velocity such as to produce ionization, as is probably the case in the cathode dark space; 
Potential at the Electrodes in Vacuum-tube Discharge. 499 if not, as is probably the case in the negative glow, the presence there of the walls of the tube will cause with the

Fig. 6.

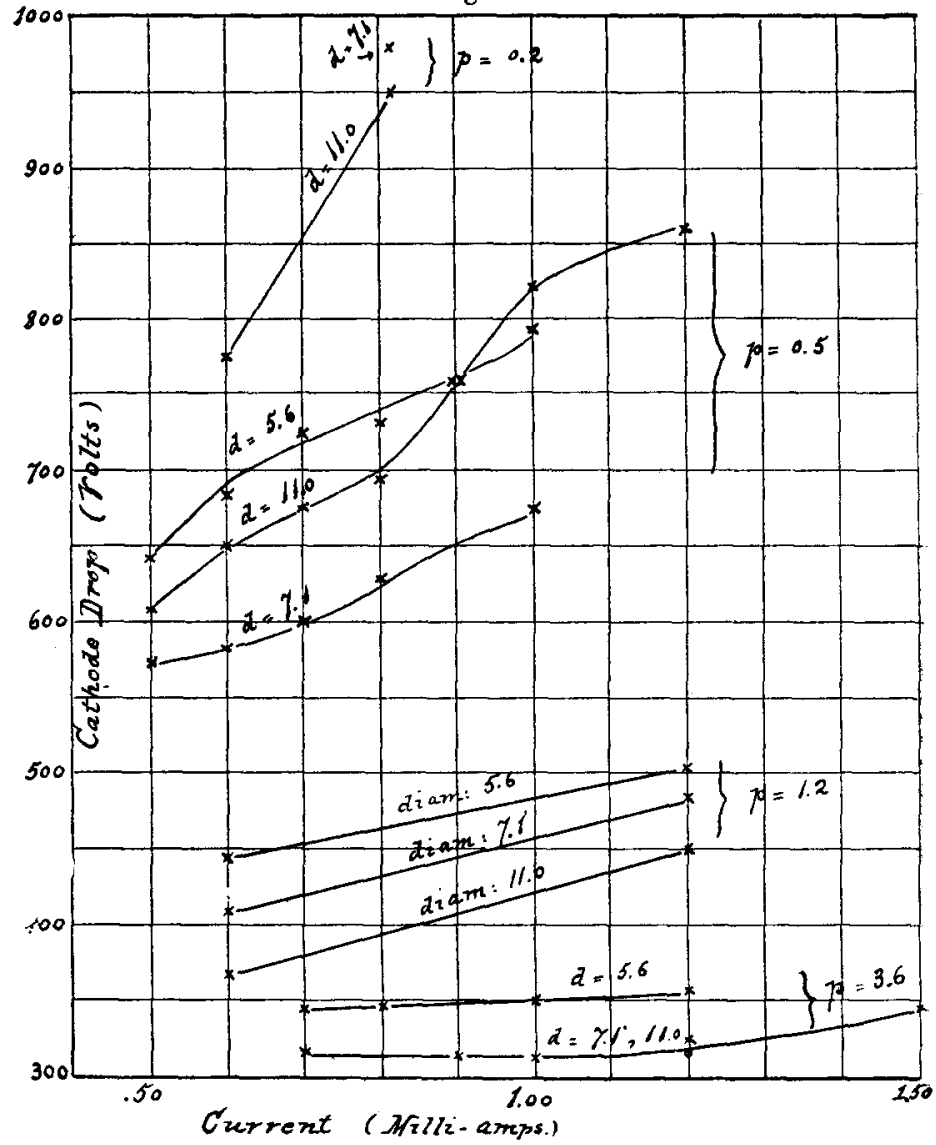

same current a smaller degree of ionization, and hence through the thereby increased velocity of the discharging ions a greater cathode drop than either when the walls are bronght into the cathode dark space or lie beyond the negative glow.

Effect of Tinfoil-coating on Tube surrounding the Cathode.

The cathode drop in the foregoing experiments was found under certain conditions to be very greatly increased when a sheet of tinfoil was wrapped around the tube opposite the discharging-surface of the cathode. The effect is inappreciable until the negative glow expands to, and is confined by 
the walls of the tube. It increases then very rapidly with decreasing gas-pressure, so that with a source of limited P.D. it soon prevents the passage of a current through the tube. Under these conditions the tube emits a hissing tone when the current is passing, and the cathode surface rapidly disintegrates, as shown by the deposit on the walls of the tube. If the current be reversed so that the disk serves as cathode, the presence of the tinfoil does not produce the slightest effect.

These phenomena may be explained by assuming a condenser-effect in which the cylinder cathode surface and the tinfoil surrounding the tube are the two surfaces of the condenser. With unconfined negative glow the highly conducting gas screens off the electrostatic forces which would otherwise act between the condenser-surfaces. When, however, by confining the glow the ionization is reduced, the condenser-effect enters, increasing the velocity with which the positive ions move up to the cathode, and thereby increasing their resistance to discharge causes for the same terminal P.D. a decreased current, as observed. With the current reversed the negative glow is not only unconfined in its expansion, but the condenser-effect acts on the ions moving up to the anode instead of the cathode, either of which would prevent any observable change due to the presence of the coating.

\section{Fffect of a Magnetic Field on the Electrode Drop.}

The effect of a magnetic field on the discharge has been studied by different observers. The following experiments were made to gain a more definite knowledge of the effect of a magnetic field on the electrode drop.

A tube of form shown in fig. 7 was used. A disk-electrode A, of aluminium, was inlaid in guttapercha. The drop at this could be obtained by means of an adjustable wire $\mathrm{W}$. A ponderous magnet being used, the tube was provided with a ground-joint T, so that without shifting it the electrode could be rotated to any desired direction with respect to that of the magnetic field.

At the Cathode.-In Table 1II. the effect of the field on the cathode drop (the P.D. between the cathode and the negative glow) is given, and the results plotted in fig. 8 (p. 502). They are independent of the direction of the field, and were taken at those pressures at which the field appears to have no influence on the distribution of current at the cathode. At a pressure of $1.8 \mathrm{~mm}$. a field of 760 lines per sq. $\mathrm{cm}$. produces an inappreciable effect; at $0.5 \mathrm{~mm}$. a field of 650 lines reduces the drop about 8 volts ; at $0.2 \mathrm{~mm} ., 20$ volts; at a much lower pressure aboüt 200 volts. The decrease seems 


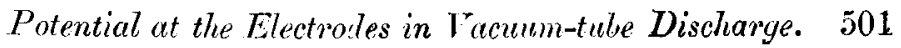

ling. 7.

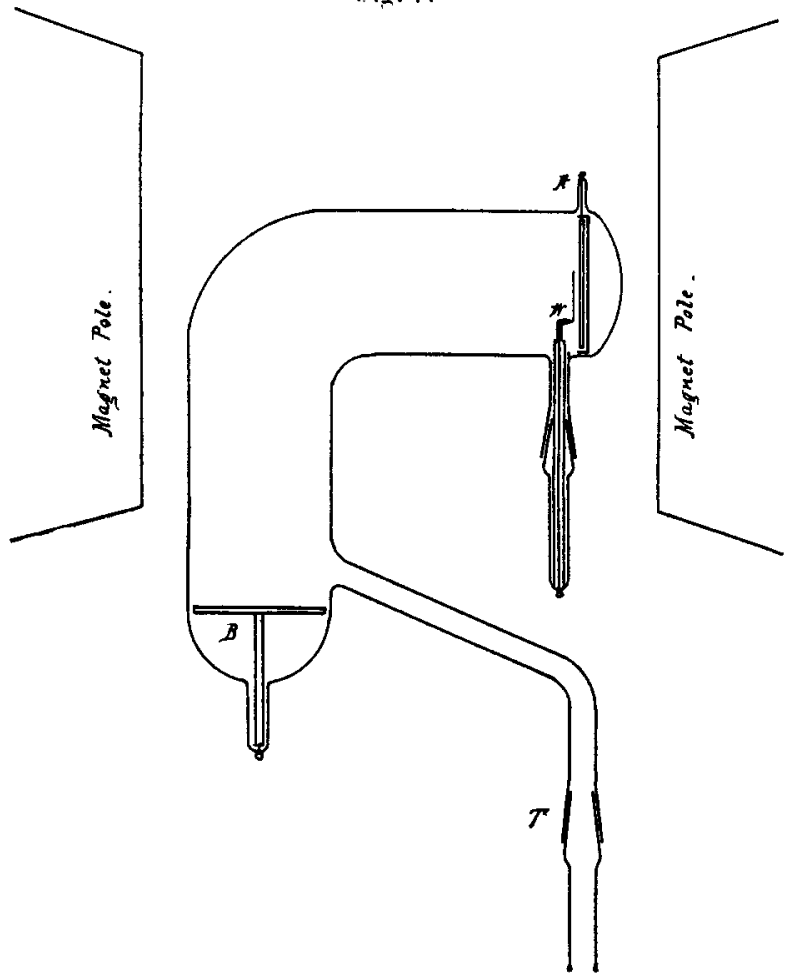

Table III.-Effect of a Magnetic Field on Cathode Drop at various Gas-Pressures.

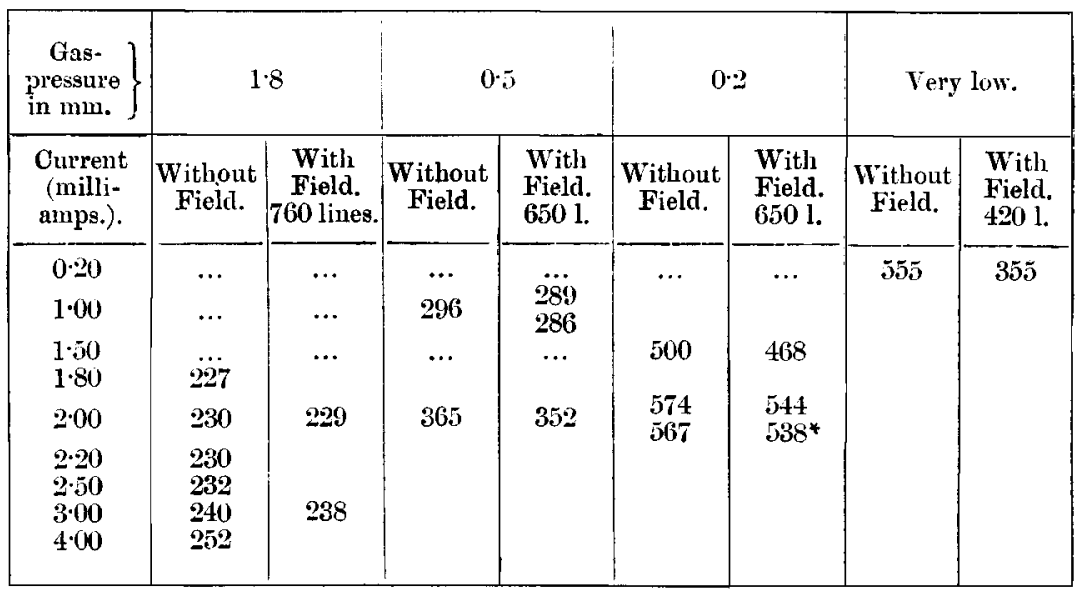

* At this pressure the gas deteriorates with currents of the given magnitude more or less rapidly. 
502 Prof. Skinner on Conditions controlling the Drop of very nearly independent of the current, a comparatively slight increase with current being registered.

Fig. 8.

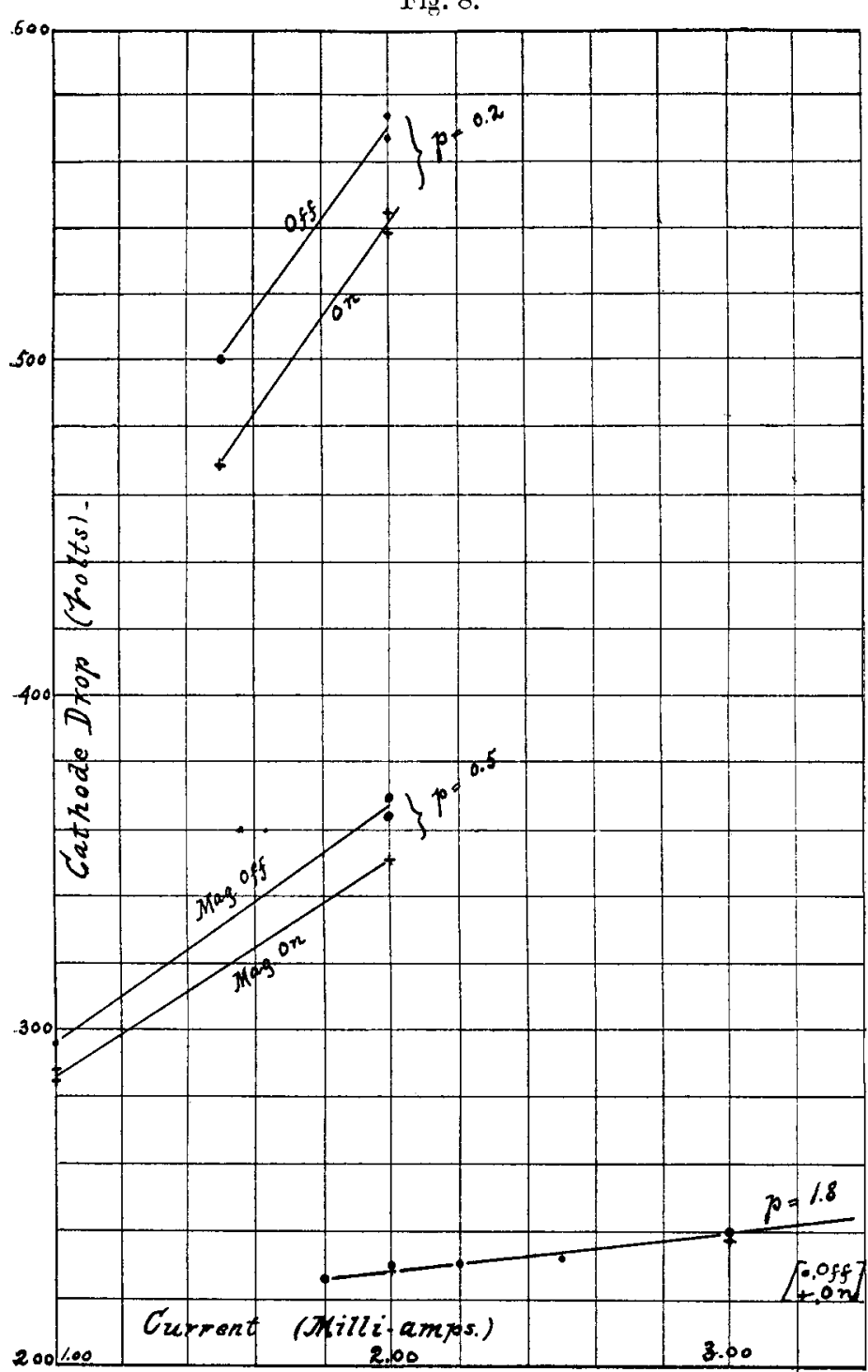

Owing to the limited battery available the observations here are not as complete as could be desired, yet they show 
Potential at the Electrodes in Vacuum-tule Discharre. 503

beyond a doubt that the effect of a magnetic field on the cathode drop increases without limit as the gas-pressure is reduced.

At the Anode.-The effect of the magnetic field on the anode drop seems, as in other cases, to be controlled by its effect on the gas-gradient. The results given in Table IV.

Table 1V.-Effect of Magnetic Field on Anode Drop. Gas-pressure $0.5 \mathrm{~mm}$. Field-intensity 600 . Current $3 \mathrm{~m}$.a.

\begin{tabular}{|c|c|c|c|}
\hline & $\begin{array}{l}\text { Drop at } \\
\text { Anode. }\end{array}$ & $\begin{array}{l}\text { P.D. between } \\
\text { Anode and } \\
\text { Neg. Glow. }\end{array}$ & $\begin{array}{l}\text { P.D. in } \\
\text { Gas. }\end{array}$ \\
\hline Mag. on .......... & $50 \cdot 6$ & & \\
\hline Mag. off .......... & $37 \cdot 0$ & & \\
\hline Mag. on ......... & $5 \overline{5}$ & & \\
\hline Mag. off......... & $\cdots$ & $18 \overline{3}$ & 148 \\
\hline Mag. on .......... & $\cdots$ & 265 & 212 \\
\hline
\end{tabular}

are typical. They are intended to show the relation between anode drop and the gradient in the gas, but on account of the form of the tube being unsuitable for conclusive results on this point, only a few observations were taken. With the current passing from $\mathrm{A}$ as anode, the anode drop was obtained with and without magnetic field in the sequence recorded. The current was then reversed, and the difference of potential between the anode $B$ and the negative glow at $W$ measured. The difference between this value and the corresponding anode drop, with and without field, gives the total drop in the gas in each case. Without making a gross error we may assume this to be proportional to the gradient near the anode which drives the negative ion into the anode field, in that this is proportional to the drop in the positive column. Referring to the Table it is observed that the values of the anode drop, $52 \cdot 8$ (mean value) and 37 , with and without field respectively, bear exactly the same ratio to each other as the corresponding values of the P.D. 212 and 148 in the gas. The accuracy of this ratio is considered accidental.

'The very large effect of the magnetic field on the P.D. in gases at low pressures, as observed by Almy *, is most likely to be attributed to the effect on the cathode drop greatly overshadowing that on the rest of the path.

It is probable that the direct effect of the field on the * J. E. Almy, Proc. Camb. Phil. Soc. vol. xi. pt. iii. 
anode drop is, as at the cathode, to slightly reduce it, but this is greatly overweighed by the indirect effect produced by the increased potential gradient in the gas.

The effect of a magnet on the cathode drop is probably to be ascribed to a factor which has been ignored in the foregoing considerations, namely, to the electromagnetic inertia of the ions, in that the magnetic field in constraining the oscillations of the ions facilitates their discharge.

Physical Laboratory, University of Nebraskin, Iincoln.

ILIV. On the Law of Atomic Weights. 1 forecust.

To the Editors of the Philosophical Magazine. Gentlemen,

TYHE letter on the Law of Atomic Weights which you were so good as to publish last month, was necessarily limited to a description of results arrived at several years ago, along with the insertion upon a diagram which had been constructed in 1888, of a series of elements since discovered.

To those earlier results I request you to allow me to add a forecast, which I desire to put forward in the hope that the appropriate laboratory tests may be applied to it.

In the diagram reproduced in Plate IV. of last month's magazine, shaded prominences were introduced to point out the elements of greatest atomic volume in the solid state, and shaded sectors to indicate those of least atomic volume. In 1888 , when that diagram was designed, it was the elements on sesqui-radius 1 that were preeminent in atomic volume amongst the elements then known. But now that sesquiradius 16 is occupied, the diagram suggests, and appears to suggest with considerable emphasis, if we recognize that the physical properties of the elements are controlled by general laws, that the column of shaded prominences on sesqui-radins 1 should be shifted to sesqui-radius 16 . 'This would mean that it is the new elements on sesqui-radius 16 , and not the elements on sesqui-radius 1, which possess the greatest atomic volume in the solid state.

To ascertain by experiment whether this is so in the case of helium would probably overtask the most refined methods of low-temperature research yet known. But it ought to be possible to determine the specific gravity in the solid state of xenon, krypton, argon, and neon; and if the forecast is found to be correct in regard to these four elements, its fulfilment will 